\title{
Composição química e de fatores antinutricionais de frutos de bocaiuva
}

\section{Chemical composition and factors antinutritional of bocaiuva fruit}

\author{
Cláudia Leite Munhoz $\left.{ }^{1}{ }^{*}\right)$ \\ Rita de Cássia Avellaneda Guimarães ${ }^{2}$ \\ Vanessa Taís Nozaki ${ }^{3}$ \\ Eliana Janet Sanjinez-Argandoña ${ }^{4}$ \\ Maria Lígia Rodrigues Macedo 5
}

\section{RESUMO}

Muitos frutos regionais são usados na elaboração de produtos alimentícios, no entanto ainda são poucos os trabalhos científicos a respeito de suas características químicas e do valor nutritivo. Este trabalho teve como objetivo determinar a qualidade nutricional da polpa e da amêndoa de bocaiuva (Acrocomia aculeata (Jacq.) Lodd.). As análises de umidade, proteína, lipídios, açúcares, fibra alimentar e cinzas foram realizadas utilizandose metodologias consagradas na literatura especializada. Os minerais e os aminoácidos foram quantificados analiticamente e o valor energético total foi estimado conforme os valores de conversão de Atwater. Os fatores antinutricionais foram determinados somente para a amêndoa do fruto. Os resultados das médias da análise centesimal da polpa e amêndoa de bocaiuva foram, em g. $100 \mathrm{~g}^{-1}$ : umidade de 49,20 e 12,1, proteína de 3,34 e 15,80, lipídeos de 30,38 e 55,55, cinzas 3,26 e 2,00, carboidratos totais de 9,31 e 1,11 e fibra alimentar 24,30 e 15,57, respectivamente. O valor calórico total é de 418,74 e 593,71 kcal.100 $\mathrm{g}^{-1}$ para polpa e amêndoa, respectivamente. Nas amêndoas, não foram encontrados inibidores de tripsina, quimotripsina e presença de lectinas. A polpa apresentou todos os aminoácidos essenciais e a amêndoa apresentou a treonina como o aminoácido limitante. Quanto aos minerais, a polpa e a amêndoa apresentaram

Dra.; Saúde e Desenvolvimento; Universidade Federal de Mato Grosso do Sul, UFMS, Brasil; Professor EBTT no Instituto Federal de Educação, Ciência e Tecnologia de Mato Grosso do Sul, IFMS, Brasil; Endereço: Instituto Federal de Educação, Ciência e Tecnologia de Mato Grosso do Sul, Campus Coxim. Rua Salime Tanure s/n, Santa Tereza, 79400000 - Coxim, MS - Brasil; E-mail: clmunhoz@yahoo.com.br

$\left({ }^{*}\right)$ Autora para correspondências

2 Dra.; Saúde e Desenvolvimento; Universidade Federal de Mato Grosso do Sul, UFMS, Brasil; Professor Adjunto na Universidade Federal de Mato Grosso do Sul, UFMS, Brasil; Endereço: Universidade Federal de Mato Grosso do Sul, Faculdade de Ciências Farmacêuticas, Alimentos e Nutrição. Av. Costa e Silva - Cidade Universitária, 79070900 - Campo Grande, MS - Brasil; E-mail: ritaguimaraes@yahoo.com.br

3 Dra.; Saúde e Desenvolvimento; Universidade Federal de Mato Grosso do Sul, UFMS, Brasil; Docente do CEI - Centro Educacional Integrado, CEI, Brasil; Endereço: R. Brasil, 840 - Jardim Laura, Campo Mourão - PR, 87301-140; E-mail: vanessatais@bol.com.br

4 Dra.; Engenharia de Alimentos; Universidade Estadual de Campinas, UNICAMP, Brasil; Professora orientadora em cursos de Pós-Graduação da UFGD e líder do Grupo de Estudos em Produtos e Processos Agroindustriais do Cerrado; Endereço: Universidade Federal da Grande Dourados, Faculdade de Engenharia. Rua João Rosa Góes - de 0983/984 ao fim, Vila Progresso -79825070 - Dourados, MS - Brasil; E-mail:elianaargandona@ufgd.edu.br

5 Dra.; Ciências Biológicas; Universidade Federal de São Paulo, UNIFESP, Brasil; DIRETORA FACFAN na Universidade Federal de Mato Grosso do Sul, UFMS, Brasil; Endereço: Universidade Federal de Mato Grosso do Sul, Departamento de tecnologia de Alimentos e da Saúde-DTA. Cidade Universitária, 79070900 - Campo Grande, MS - Brasil E-mail: bioplant@terra.com.br 
valores consideráveis, de ferro, cálcio e zinco. Os frutos da bocaiuva podem ser fontes alternativas de nutrientes. Sugere-se, pois, sua utilização em produtos alimentícios valorizando o uso de frutos nativos na formulação de novos produtos.

Palavras-chave: Acrocomia aculeata, nutrientes, frutos do cerrado

\section{ABSTRACT}

Many regional fruits are used in the preparation of food products; however, there are few scientific studies on their chemical composition and nutritive value. This study aimed to determine the nutritional quality of the pulp and almond of bocaiuva (Acrocomia aculeata (Jacq.) Lodd.). The moisture, protein, lipids, sugars, dietary fiber and ash were carried out using methods traditionally used in the literature. The minerals and amino acids were quantified analytically and total energy intake was estimated as the Atwater conversion values. The antinutritional factors were determined only for the almond of the fruit. The mean values of the proximate analysis pulp and almond of bocaiuva were in $\mathrm{g} .100 \mathrm{~g}^{-1}$ : moisture 49.20 and 12.1 , protein of 3.34 and 15.80 , lipids 30.38 and 55.55, ash 3.26 and 2.00, total carbohydrates 9.31 and 1.11, dietary fiber 24.30 and 15.57, respectively. The total caloric value is 418.74 and $593.71 \mathrm{kcal} 100 \mathrm{~g}^{-1}$ for pulp and almond, respectively. Almonds were not found in trypsin and chymotrypsin inhibitors and the presence of lectins. The pulp showed all essential amino acids and almonds presented as the limiting amino acid threonine. As minerals, pulp and almond had considerable amounts of iron, calcium and zinc. The fruits of bocaiuva may be sources of nutrients, it is suggested their use in food products enhancing the use of native fruits in the formulation of new products.

Keywords: Acrocomia aculeata, nutrients, fruits of the cerrado

\section{Introdução}

O Cerrado brasileiro é considerado um dos hotspot mundial de biodiversidade de plantas frutíferas nativas ou adaptadas, com potencial promissor para o aproveitamento agroindustrial. Os frutos das espécies nativas do Cerrado são considerados exóticos e apresentam atrativos sensoriais como cor, sabor e aroma peculiares, ainda pouco explorados comercialmente e relativamente pouco conhecidos pela ciência (AQUINO et al., 2008; OLIVEIRA-FILHO; MEDEIROS, 2008; SILVA et al., 2008). O aproveitamento tecnológico de espécies frutíferas nativas pode constituir fonte de alimentos para o país (RAMOS et al., 2008).

A bocaiuva (Acrocomia aculeata (Jacq.) Lodd) é um fruto que apresenta potencial de aproveitamento tecnológico alimentício. É comercializada, principalmente in natura, em mercados locais. O fruto, também conhecido por macaúba, pertence à família Arecaceae, sendo encontrado em quase todo o Brasil. No Estado de Mato Grosso do Sul, predomina nos campos abertos (AQUINO et al., 2008; LORENZI, 2006). A polpa contém quantidade significativa de lipídeos, cálcio e fibra alimentar e a amêndoa possui considerável quantidade de proteínas, lipídeos, fibras e minerais (HIANE et al., 2006; SILVA et al., 2008). Embora o fruto possua elevado teor de proteínas, as propriedades antinutricionais ainda são pouco estudadas. 
As proteínas de reserva, como as lectinas e os inibidores de proteases, encontradas principalmente nas sementes das plantas, têm sido estudadas em leguminosas, como o feijão, a soja e o amendoim, e em cereais, como o trigo e a cevada (SGARBIERI, 1996). Nas plantas, essas proteínas estão associadas ao mecanismo de defesa, apresentando propriedades bactericida, fungicida e inseticida (FREIRE et al., 2002). Na dieta humana ou animal, são conhecidos como fatores antinutricionais, podendo provocar efeitos fisiológicos adversos ou diminuir a biodisponibilidade de nutrientes (SGARBIERI, 1996).

Os inibidores de proteases são proteínas de ampla distribuição no reino vegetal, capazes de inibir as atividades da tripsina, quimo tripsina, amilase e carboxipeptidase; as lectinas, por sua vez, são proteínas não pertencentes ao sistema imunológico, porém capazes de reconhecer sítios específicos em moléculas e ligar-se reversivelmente a carboidratos, sem alterar a estrutura covalente das ligações glicosídicas dos sítios (SGARBIERI, 1996).

A avaliação das proteínas nos alimentos tem influência direta sobre o seu uso e a sua aceitabilidade, pois está relacionada com a qualidade e a segurança no contexto da Saúde Pública e da Nutrição (HIANE et al., 2006). Diante disso, o objetivo deste trabalho foi determinar a composição química e os fatores antinutricionais de frutos de bocaiuva.

\section{Material e métodos}

\section{Amostra dos frutos}

Os frutos de bocaiuva foram provenientes do município de Vicentina, Estado de Mato

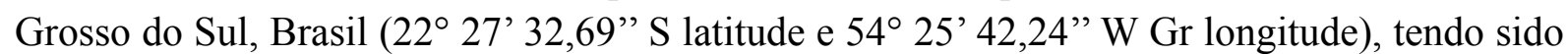
coletados no período de outubro a dezembro de 2009 e lavados, sanitizados com dicloro s. triazinatriona sódica di-hidratada, da marca Sumaveg, na concentração de 0,66\% por 10 min. Em seguida, os frutos foram descascados e despolpados manualmente. Os tegumentos foram quebrados com uso de uma morsa e as amêndoas foram retiradas manualmente. A polpa do fruto foi desidratada em secador de bandejas, com fluxo de ar a $45^{\circ} \mathrm{C}$ por, aproximadamente, $8 \mathrm{~h}$. A polpa desidratada e a amêndoa foram trituradas e tamisadas em peneira com abertura de malha de 60 mesh.

Parte da farinha da amêndoa da bocaiuva foi delipidada com éter de petróleo, posteriormente, homogeneizada em solução tampão fosfato $\mathrm{pH} 7,6$, sob agitação, durante $2 \mathrm{~h}$, à temperatura ambiente. A solução foi centrifugada a $17000 \times$ g durante $30 \mathrm{~min}$, o sobrenadante foi dialisado contra água destilada durante 24 h e liofilizado para a realização das análises posteriores.

\section{Composição quimo centesimal}

As análises da composição quimo centesimal da polpa desidratada e da amêndoa da bocaiuva foram realizadas em triplicata de acordo com as normas analíticas do Instituto Adolfo Lutz (BRASIL, 2005). A análise da umidade foi realizada em estufa, a $105^{\circ} \mathrm{C}$ até peso constante. $\mathrm{A}$ análise do resíduo mineral fixo foi realizada por incineração em mufla a $550^{\circ} \mathrm{C}$. $\mathrm{O}$ teor de lipídeos totais foi determinado por extração com éter etílico em aparelho de Soxhlet. A proteína foi determinada pelo conteúdo de nitrogênio total, segundo método do micro Kjedahl, e o fator de 6,25 usado para a conversão do teor de nitrogênio em proteína bruta. Os carboidratos foram determinados pelo método de Lane-Eynon, baseado na oxidação do cobre. O teor de 
fibra alimentar foi determinado pelo método enzímico-gravimétrico. $\mathrm{O}$ valor energético total proveniente dos nutrientes foi expresso em quilocalorias (kcal), estimada a partir dos fatores de conversão de Atwater: $\mathrm{kcal}=(4 \mathrm{x}$ g proteína $)+(4 \mathrm{x}$ g carboidratos $)+(9 \mathrm{xg}$ lipídios $)$ (MERRIL, WATT, 1973).

A quantificação das proteínas solúveis do material liofilizado da amêndoa de bocaiuva foi estimada pelo método de Bradford (1976), utilizando albumina sérica bovina (BSA) como padrão. A leitura das absorbâncias foi realizada em espectrofotômetro Spectrum UV a $595 \mathrm{~nm}$.

\section{Fatores antinutricionais}

As análises desses fatores foram realizadas somente para a amêndoa de bocaiuva. As atividades inibitórias foram realizadas por meio de ensaio enzimático com tripsina bovina, e substrato $\mathrm{N} \alpha$-benzoil-DL-arginina-paranitroanilida (BApNA), e quimotripsina pancreática bovina, e substrato N-benzoil-L-tirosina-paranitroalida (BTpNA). A leitura foi realizada em espectrofotômetro a $410 \mathrm{~nm}$ (MACEDO et al., 2003).

Os ensaios de hemaglutinação (lectina) foram realizados em placas de microtitulação U, utilizando diluições seriadas de $50 \mu \mathrm{L}$ de $0,15 \mathrm{M} \mathrm{NaCl}, 50 \mu \mathrm{L}$ dos extratos totais e $50 \mu \mathrm{L}$ de suspensão a $2 \%$ de eritrócitos humanos do tipo A (FREIRE et al., 2002).

Eletroforese em gel de poliacrilamida/ poliacrilamida-dodecilsulfato de sódio

A análise do perfil proteico foi realizada somente para a amêndoa da bocaiuva, segundo Laemmli (1970). O marcador padrão utilizado apresentava massas moleculares variando de 15 a $150 \mathrm{kDa}$.

\section{Composição de aminoácidos}

As análises de aminoácido foram conduzidas em analisador de aminoácidos PicoTag (Waters), como descrito por Henrikson e Meredith (1984). O material liofilizado da polpa e da amêndoa de bocaiuva foi hidrolisada com $6 \mathrm{M} \mathrm{HCl} /$ fenol $1 \%$ a $106^{\circ} \mathrm{C}$ durante $24 \mathrm{~h}$. O hidrolisado reagiu com $20 \mu \mathrm{L}$ de solução de derivação (metanol: trietilamina: água: fenilisotiocianato, 7:1:1:1, v/v) por $1 \mathrm{~h}$, à temperatura ambiente. Após derivatização na pré-coluna, os aminoácidos foram identificados em coluna de HPLC, em fase reversa, comparando-se os tempos de retenção dos aminoácidos da amostra com os dos padrões (Pierce). Resíduos de cisteína foram quantificados como ácido cisteico. Com os valores da composição em aminoácidos foi estimado o escore de aminoácidos essenciais (EAE), conforme Equação 1.

$$
\begin{aligned}
E A E(\%)= & \frac{\text { aminoácido mais limitante na proteína teste }}{\text { mesmo aminoácido no padrão de referência } F A O / W H O} \\
& \times 100
\end{aligned}
$$

\section{Conteúdo de minerais}

O conteúdo de minerais foi determinado por meio de digestão ácida em ácido nítrico concentrado, de acordo com Salinas e Garcia (1985). Os teores de cálcio, magnésio, ferro, manganês, zinco e cobre foram determinados em espectrofotômetro de absorção atômica com acetileno 
comprimento de onda e split de $422,7 \mathrm{~nm}$ e $0,7 \mathrm{~mm}, 285,2 \mathrm{~nm}$ e $0,7 \mathrm{~mm} ; 248,3 \mathrm{~nm}$ e $0,2 \mathrm{~mm}$; $279,5 \mathrm{~nm}$ e $0,2 \mathrm{~mm} ; 213,9 \mathrm{~nm}$ e $0,7 \mathrm{~mm} ; 324,7 \mathrm{~nm}$ e $0,7 \mathrm{~mm}$, respectivamente. Os teores de sódio e de potássio foram determinados por fotômetro de chama, nos comprimentos de onda de $589 \mathrm{~nm}$ e $768 \mathrm{~nm}$, respectivamente. $\mathrm{O}$ teor de fósforo foi determinado em espectrofotômetro de luz visível no comprimento de onda de $420 \mathrm{~nm}$.

\section{Análise estatística}

Os resultados das análises químicas foram expressos pela média e desvio padrão e foram submetidos à análise de variância (ANOVA) e teste de diferença entre médias (Teste de Tukey, $\mathrm{p}<0,05)$.

\section{Resultados e discussão}

Os valores encontrados na composição centesimal para polpa e amêndoa de bocaiuva estão apresentados na Tabela 1 .

Tabela 1. Composição centesimal de polpa e amêndoa de bocaiuva $\left(\mathbf{g} \cdot 100 \mathrm{~g}^{-1}\right)$.

\begin{tabular}{ccc}
\hline Componentes $^{1}$ & Polpa & Amêndoa \\
Umidade & $49,20 \pm 0,11$ & $12,1 \pm 0,01$ \\
Proteína & $3,34 \pm 0,01$ & $15,80 \pm 0,01$ \\
Lipídeos & $30,38 \pm 0,33$ & $55,55 \pm 0,66$ \\
Cinzas & $3,26 \pm 0,02$ & $2,00 \pm 0,50$ \\
Açúcares totais em glicose & $9,31 \pm 0,14$ & $1,11 \pm 0,03$ \\
Amido em glicose & $23,65 \pm 0,46$ & $6,48 \pm 0,38$ \\
Fibras & $24,30 \pm 1,07$ & $15,57 \pm 0,50$ \\
Valor calórico total (kcal.100 $\mathrm{g}^{-1}$ ) & $418,74 \pm 0,24$ & $593,71 \pm 0,27$ \\
\hline es expressos em base seca, exceto para a umidade. Dados apresentados como média \pm desvio padrão.
\end{tabular}

A polpa da bocaiuva apresentou-se rica em lipídeos, em carboidratos e em fibras, fornecendo, aproximadamente, $418,74 \mathrm{kcal} .100 \mathrm{~g}^{-1}$ o que corresponde a $21 \%$ das necessidades calóricas de um adulto, com dieta de $2000 \mathrm{kcal} \mathrm{e} 81 \%$ das necessidades de fibra alimentar (BRASIL, 2003). A polpa também apresentou teor elevado de minerais, representado pelo resíduo mineral fixo. Comparando-se com os valores reportados por Ramos et al. (2008) para a polpa de bocaiuva, o teor de lipídeos foi inferior (17,31 g.100 g-1 em base seca) e o teor de açúcares totais foi superior (20,29 g.100 g ${ }^{-1}$ em base seca). Com isso, o valor calórico também ficou inferior (356,67 kcal. 100 $\mathrm{g}^{-1}$ em base seca). Silva et al. (2008) reportaram para a polpa de bocaiuva, valores de proteínas e açúcares (4,20 e 53,38 g.100 g-1 em base seca, respectivamente) superiores ao deste trabalho e valor de lipídeos inferior (22,73 g.100 g-1 em base seca). A diferença entre frutos de mesma espécie, mas de diferentes regiões, é explicada pela influência que o solo, a adubação, o clima e outros fatores ambientais exercem na sua composição.

Os componentes majoritários para a amêndoa de bocaiuva foram proteína, lipídeos e fibras. Hiane et al. (2006) reportaram valores semelhantes aos encontrados neste estudo para amêndoa de bocaiuva, apresentando apenas teor de umidade inferior $\left(6,5 \mathrm{~g} .100 \mathrm{~g}^{-1}\right)$. O valor calórico da amêndoa de bocaiuva foi semelhante ao encontrado por Lima et al. (2007) para a amêndoa de pequi. Em amêndoas de Acrocomia intumescens, foram reportados valores inferiores ao deste estudo para proteínas e lipídeos (8,92 e 51,68 g.100 g em base seca) (BORA, ROCHA, 2004). 
A amêndoa de bocaiuva tem com alto teor de proteína, pois apresenta, aproximadamente, $21 \%$ da ingestão diária recomendada (IDR) por 100g em todos os segmentos: adultos, crianças, lactentes, gestantes e lactantes (BRASIL, 1998).

Um alimento é considerado com alto teor de fibra quando contém acima de $6 \mathrm{~g} \cdot 100 \mathrm{~g}^{-1} \mathrm{e}$ como fonte, quando seu teor está acima de $3 \mathrm{~g} \cdot 100 \mathrm{~g}^{-1}$, portanto as amêndoas de bocaiuva podem ser consideradas com alto teor de fibra, além de contribuir com mais de $50 \%$ da ingestão diária recomendada (BRASIL, 1998).

O consumo da polpa e da amêndoa de bocaiuva pode trazer benefícios à saúde da população, uma vez que o consumo regular de fibra alimentar, na dieta, está relacionado com a redução do risco de diversas patologias (MICHELS et al., 2005).

As frações da bocaiuva (polpa e amêndoa) podem contribuir, em proporções consideráveis, com a ingestão dietética recomendada, podendo ser utilizadas no processamento de alimentos, agregando valor ao produto final.

Os conteúdos de proteínas, determinado pelo método de Bradford (1976), da amostra liofilizada, foi de $90 \%$ para a amêndoa, indicando que a amêndoa é rica em proteína solúvel. Os fatores antinutricionais foram determinados somente para a amêndoa, pois a polpa apresentou baixo conteúdo de proteínas.

A qualidade da proteína é afetada por fatores antinutricionais que interagem com células do trato intestinal, tais como os inibidores de proteases e lectinas, que reduzem a digestibilidade da proteína e a absorção de aminoácidos. Salvo destruídos ou inativados pelo calor ou por algum outro tratamento adequado, essas substâncias podem exercer efeitos fisiológicos adversos quando ingeridas pelo homem e animais (SGARBIERI, 1996). No presente estudo, não foi observada inibição ou hemaglutinação da amostra testada, revelando níveis não detectáveis de inibidores de tripsina, quimotripsina e lectina (Tabela 2). Esse é um resultado relevante, pois sementes de leguminosas como a soja contêm níveis altos de inibidores de proteases, e tem sido verificada em modelos animais de experimentação, a diminuição do crescimento, a hipertrofia e hiperplasia pancreática (GARCIA et al., 2004). A maioria desses compostos inibem as enzimas digestivas e podem reagir com aminoácidos essenciais, limitando o uso de sementes inteiras em produtos alimentícios. As lectinas se ligam à mucosa intestinal, prejudicando a digestão e a absorção dos nutrientes, o que reduz a digestibilidade da proteína, inibindo as enzimas digestivas (VALLILO et al., 1998). Hiane et al. (2006) avaliaram as frações de globulina e glutelina da amêndoa de bocaiuva e, também, não encontraram atividade inibitória de proteases e a atividade hemaglutinante (foi muito baixa). Denadai et al. (2007), em amêndoas de sapucaia e Silva e Fernandes (2011), em amêndoas cruas e torradas de chichá, obtiveram resultados semelhantes ao do presente estudo.

Tabela 2. Fatores antinutricionais na amêndoa de bocaiuva. *

\begin{tabular}{lccc}
\hline Amostra & Lectina & Inibidor de tripsina & Inibidor de quimotripsina \\
\hline Amêndoa & ND & ND & ND \\
\hline
\end{tabular}

*ND: não detectado.

De acordo com a Figura 1, a amêndoa de bocaiuva apresenta diferentes polipeptídeos que abrangem uma ampla faixa de massas moleculares, sendo a maior concentração em torno de 75 $\mathrm{kDa}$. 


\section{Figura 1. Perfil eletroforético em SDS-PAGE. M: marcador de massa molecular. 1: material liofilizado de amêndoa de bocaiuva.}

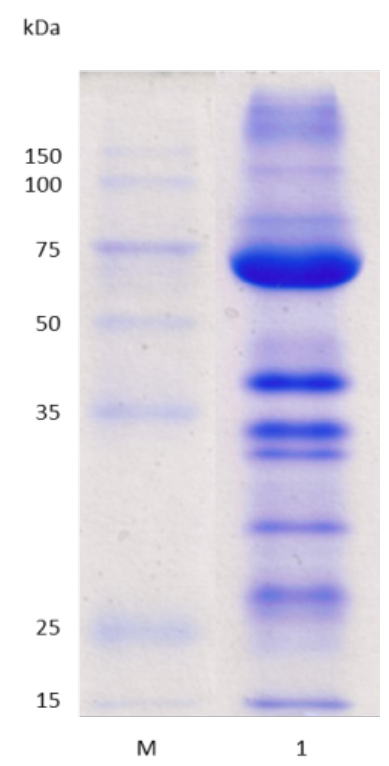

A composição de aminoácidos da polpa e da amêndoa de bocaiuva, os requerimentos mínimos estabelecidos para escolares e adultos (FAO,1991) e o escore de aminoácidos encontramse na Tabela 3. A polpa e a amêndoa de bocaiuva são ricas em ácido aspártico e glutâmico e arginina. Valores semelhantes foram encontrados por Amaya-Farfan et al. (1986), Bora et al. (2001) e Bora e Rocha (2004), para palmeiras Astocaryum acaule Mart, Astocaryum vulgare Mart e Acrocomia intumescens, respectivamente. Outros aminoácidos não essenciais como a alanina, glicina, prolina e serina, as quais também, apresentaram boas concentrações.

Em relação aos aminoácidos essenciais, a polpa apresentou melhor perfil, pois possui todos os aminoácidos essenciais em quantidades superiores das recomendadas pela FAO (1991), com exceção do triptofano que não foi determinado neste trabalho. Em outros trabalhos com frutos de palmeiras com Astocaryum tucuma, Mart (HALL et al., 1980), Astocaryum vulgare, Mart (BORA et al., 2001), Acrocomia intumescens, (BORA; ROCHA, 2004) e Syagrus oleracea, Mart (BORA; MOREIRA, 2003), as polpas dos frutos continham grandes quantidades de aminoácidos essenciais. 
Tabela 3. Perfil dos aminoácidos da polpa e da amêndoa de bocaiuva, em mg. - $^{-1}$ de proteína

\begin{tabular}{lcccc}
\hline \multicolumn{1}{c}{ Aminoácidos } & Polpa & Amêndoa & Escolar & Adulto \\
\hline Ácido aspártico & 106,5 & 56,0 & & \\
Ácido glutâmico & 95,2 & 208,3 & & \\
Serina & 59,3 & 56,1 & & \\
Glicina & 74,8 & 94,1 & & \\
Histidina & 27,3 & 19,2 & 16 & 15 \\
Arginina & 78,9 & 130,0 & & \\
Treonina & 50,2 & 17,6 & 25 & 23 \\
Alanina & 33,4 & 65,3 & & \\
Prolina & 91,9 & 52,1 & & 38 \\
Fenilalanina + tirosina & 119,3 & 50,1 & 41 & 39 \\
Valina & 47,5 & 57,9 & 40 & 30 \\
Metionina + cisteína & 125,9 & 28,9 & 24 & 59 \\
Isoleucina & 41,2 & 26,8 & 31 & 45 \\
Leucina & 67,3 & 59,5 & 61 & \\
Lisina & 58,5 & 78,1 & 48 & \\
Escore limitante escolar (\%) & - & 70,4 & & \\
Escore limitante adulto (\%) & - & 76,5 & & \\
Aminoácido limitante escolar & - & Treonina & & \\
Aminoácido limitante adulto & - & Treonina & & \\
\hline
\end{tabular}

Fonte: FAO (1991).

A amêndoa de bocaiuva apresentou a treonina e a isoleucina como primeiro e segundo aminoácidos limitantes; os outros aminoácidos essenciais apresentaram concentrações maiores que as recomendadas pela FAO (1991). Em amêndoas de Acrocomia intumescens (BORA; ROCHA, 2004), foram encontradas somente isoleucina e fenilalanina em quantidades recomendadas pela FAO (1991), sendo deficiente no restante dos aminoácidos essenciais. Por sua vez, as amêndoas de Syagrus oleracea Mart (BORA; MOREIRA, 2003) foram deficientes apenas em isoleucina, fenilalanina e treonina.

Os frutos da bocaiuva podem ser utilizados na formulação de produtos alimentícios com alta qualidade proteica em associação com outras fontes de proteína, como em barras de cereais (MUNHOZ et al., 2014).

O conteúdo de minerais da polpa e da amêndoa de bocaiuva encontra-se na Tabela 4. 
Tabela 4. Conteúdo de minerais $\left(\mathrm{mg} .100 \mathrm{~g}^{-1}\right)$ da polpa e da amêndoa da bocaiuva (base seca).

\begin{tabular}{ccc}
\hline Minerais & Polpa & Amêndoa \\
\hline Cálcio $(\mathrm{Ca})$ & $324,61 \pm 3,11$ & $170,65 \pm 0,23$ \\
Magnésio $(\mathrm{Mg})$ & $219,90 \pm 2,15$ & $250,28 \pm 2,78$ \\
Fósforo $(\mathrm{P})$ & $41,88 \pm 0,20$ & $113,77 \pm 0,91$ \\
Potássio $(\mathrm{K})$ & $1654,45 \pm 10,34$ & $386,81 \pm 5,91$ \\
Sódio $(\mathrm{Na})$ & $4,18 \pm 0,01$ & $9,35 \pm 0,31$ \\
Ferro $(\mathrm{Fe})$ & $3,91 \pm 0,01$ & $6,08 \pm 0,22$ \\
Manganês $(\mathrm{Mn})$ & $0,64 \pm 0,01$ & $2,46 \pm 0,01$ \\
Zinco $(\mathrm{Zn})$ & $12,60 \pm 0,02$ & $4,46 \pm 0,04$ \\
Cobre $(\mathrm{Cu})$ & $0,75 \pm 0,01$ & $2,45 \pm 0,01$ \\
\hline
\end{tabular}

Um alimento é considerado com alto teor de minerais quando contém, no mínimo, 30\% da ingestão diária recomendada (IDR) de referência, em $100 \mathrm{~g}$ de alimento sólido e, como fonte, quando seu teor é no mínimo de 15\% (BRASIL, 1998). Assim, a polpa de bocaiuva possui alto teor de cálcio, magnésio, zinco e cobre e é fonte de ferro e manganês. A amêndoa, por sua vez, tem alto teor de magnésio, ferro, manganês, zinco e cobre e é fonte de cálcio e fósforo. Os frutos da bocaiuva podem contribuir em proporções consideráveis com a ingestão dietética recomendada, sendo fontes alternativas de nutrientes.

Oliveira et al. (2010) encontraram, para a polpa do pequi, teores de cálcio, magnésio, fósforo, potássio, ferro e zinco inferiores ao do presente trabalho e valores de cobre e manganês superiores. Silva et al. (2008) reportaram, para a polpa de bocaiuva, valores de cálcio, zinco e ferro inferiores aos obtidos neste trabalho, Ramos et al. (2008) encontraram, para a polpa de bocaiuva, valores inferiores para cálcio fósforo, potássio e zinco, e valores superiores ao deste trabalho para ferro, manganês e cobre. Oliveira et al. (2006), ao avaliar a polpa de bocaiuva, determinaram valores de cálcio, potássio, manganês, cobre, ferro e zinco superiores ao desta pesquisa. A diferença entre frutos de mesma espécie e em diferentes regiões pode ser explicada pela influência que os fatores ambientais exercem na composição desses frutos.

Em amêndoas de baru, Vera et al. (2009) reportaram valores de cálcio, potássio, ferro, manganês, magnésio, cobre e zinco, superiores aos da amêndoa de bocaiuva. Oliveira et al. (2010) apresentaram valores de cálcio, cobre, ferro e zinco, inferiores ao presente trabalho e magnésio, fósforo, potássio e manganês, superiores. Para amêndoas de bocaiuva de Hiane et al. (2006), somente o fósforo apresentou valores superiores e os outros minerais valores inferiores a esta pesquisa.

\section{Conclusão}

As frações polpa e amêndoa de bocaiuva mostram ser potenciais fontes de elementos nutritivos. A polpa da bocaiuva apresenta-se rica em lipídeos, em carboidratos e em fibras; a amêndoa de bocaiuva possui alto teor de proteínas, lipídeos e fibras.

Não foram encontrados inibidores de tripsina e quimotripisina e presença de lectinas na amêndoa de bocaiuva. 
Em relação aos aminoácidos essenciais, com exceção ao triptofano, a polpa possui todos os aminoácidos essenciais em quantidades superiores às recomendadas. A amêndoa de bocaiuva apresenta a treonina e a isoleucina como primeiro e segundo aminoácidos limitantes.

Os teores de minerais encontrados indicam que a polpa de bocaiuva possui alto teor de cálcio, magnésio, zinco e cobre e é fonte de ferro e manganês. A amêndoa contém alto teor de magnésio, ferro, manganês, zinco e cobre e é fonte de cálcio e fósforo.

\section{Agradecimentos}

Os autores agradecem a Capes a bolsa de doutorado concedida.

\section{Referências}

AMAYA-FARFAN, J.; RODRIGUES-AMAYA, D. B.; NOLETO CRUZ, P.; MARQUES, E. P. Fatty acid and amino acid composition of some indigenous fruits of Northeastern Brazil. Ciência e Tecnologia de Alimentos, Campinas, v.6, n. 1, p. 86-92, 1986.

AQUINO, F. G.; RIBEIRO, J. F.; GULIAS, A. P. S.; OLIVEIRA, M. C.; BARROS, C.J. S.; HAYES, K. M.; SILVA, M. R. Uso sustentável das plantas nativas do Cerrado: oportunidades e desafios. In: PARRON, L. M.; AGUIAR, L. M. S.; DUBOC, E.; OLIVEIRA-FILHO, E. C.; CAMARGO, A. J. A.; AQUINO, F. G. (Ed) Cerrado: desafios e oportunidades para o desenvolvimento sustentável. Planaltina: Embrapa Cerrados, 2008. p. 95-123.

BORA, P. S.; NARAIN, N.; ROCHA, R. V. M.; MONTEIRO, A. C.; OLIVEIRA, R. A. Characterization of the oil and protein fractions of Tucuma (Astrocaryum vulgare Mart) fruit pulp and seed kernels. Ciência y Tecnologia Alimentaria, Galícia, v. 3, n. 2, p.111116, 2001. DOI: e: http://dx.doi.org/10.1080/11358120109487654

BORA, P. S.; MOREIRA, V. R. R. Catolé palm (Syagrus oleracea Mart) fruits: fatty and amino acids composition. Grasas y Aceites, Sevilla, v. 54, 145-150, 2003. DOI: http:// dx.doi:10.3989/gya.2003.v54.i2.257

BORA, P.S.; ROCHA, R.V. M. Macaiba palm: fatty and amino acids composition of fruits. Ciência y Tecnologia Alimentaria, Galícia, v. 4, n. 3, p. 158-162, 2004. DOI: http://dx.doi.org/10.1080/11358120409487755

BRADFORD, M. M. A rapid and sensitive method for the quantification of microgram quantities of protein using the principle of protein-dye binding. Analytical Biochemistry, New York, v. 72, n. 1-2, p. 248-254, 1976. DOI: 10.1016/0003-2697(76)90527-3

BRASIL. Ministério da Saúde. Agência Nacional de Vigilância Sanitária. Portaria ${ }^{\circ}$ 27 de 13 de janeiro de 1998: Regulamento Técnico sobre a Informação Nutricional Complementar. 
BRASIL. Ministério da Saúde. Agência Nacional de Vigilância Sanitária. Resolução-RDC no 360 de 23 de dezembro de 2003. Dispõe sobre o regulamento técnico de rotulagem nutricional de alimentos embalados.

BRASIL. Ministério da Saúde. Agência Nacional de Vigilância Sanitária (ANVISA). Métodos físico-químicos para análise de alimentos. Brasília: Ministério da Saúde, 2005. 1018 p.

DENADAI, S. M. S.; HIANE, P.; MARANGONI, S.; BALDASSO, P. A.; MIGUEL, A. M. R. O.; MACEDO, M. L. R. In vitro digestibility of globulins from sapucaia (Lecythis pisonis Camb.) nuts by mammalian digestive proteinases. Ciência e Tecnologia de Alimentos, Campinas, v. 27, n. 3, p. 535-543, 2007. DOI: http://dx.doi.org/10.1590/S0101-20612007000300018

FAO/WHO. Report of a joint FAO/WHO expert consultation held in Bethseda, MD, USA. Dec 1989. Protein quality evaluation. FAO/Rome/Italy, 1991.

FREIRE, M. G. M.; GOMES, V. M.; CORSINI, R. E.; MACEDO, M. L. R. Isolation and partial characterization of a novel lectin from Talisia esculenta seeds that interferes with fungal growth. Plant Physiology and Biochemistry, Paris, v. 40, p. 61-68, 2002. DOI:10.1016/S09819428(01)01342-0

GARCIA, V. A. FREIRE, M. G.; NOVELlO, J. C.; MARANGONI, S.; MACEDO, M. L. R. Trypsin inhibitor from Poecilanthe parviflora seeds: purification, characterization, and activity against pest proteases. The Protein Journal, v. 23, n. 5, p. 343-350, 2004. DOI: 10.1023/B:JOPC.0000032654.67733.d5

HALL, N. T.; SMOOT, J. M.; KNIGHT JUNIOR, R. J.; NAGY, S. Protein and amino acid composition of ten tropical fruits by gas-liquid chromatography. Journal of Agricultural and Food Chemistry, Easton, v. 28, n. 6, p.1217-1221, 1980. DOI: 10.1021/jf60232a066

HENRIKSON, R. L.; MEREDITH, S. C. Amino acid analysis by reverse phase high performance liquid chromatography: precolumn derivatization with phenylisothiocyanate. Analytical Biochemistry, New York, v. 136, n. 1, p. 65-71, 1984. DOI:10.1016/0003-2697(84)90307-5

HIANE, P.A.; BALDASSO, P. A.; MARANGONI, S.; MACEDO, M. L. R. Chemical and nutrition evaluation of kernels of bocaiuva, Acrocomia aculeata (Jacq.) Lodd. Ciência e Tecnologia de Alimentos, Campinas, v. 26, n. 3, p. 683-689, 2006. DOI: http://dx.doi.org/10.1590/S010120612006000300031

LAEMMLI, U. K. Cleavage of structural proteins during the assembly of the head of bacteriophage T4. Nature, London, v. 227, p. 680-685, 1970. DOi:10.1038/227680a0

LIMA, A.; SILVA, A. M. O.; TRINDADE, R. A.; TORRES, R. P.; MANCINI-FILHO, J. Composição química e compostos bioativos presentes na polpa e na amêndoa do pequi (Caryocar brasiliense, Camb.). Revista Brasileira de Fruticultura, Jaboticabal, v. 29, n. 3, p. 695-698, 2007. DOI: http://dx.doi.org/10.1590/S0100-29452007000300052 
LORENZI, G. M. A. C. Acrocomia aculeata (Jacq.) Lodd. ex Mart. - Arecaceae: bases para o extrativismo sustentável. 2006. 166f. Tese (Doutorado em Agronomia) - Setor de Ciências Agrárias Universidade Federal do Paraná, Curitiba, 2006.

MACEDO, M. L. R.; FREIRE, M. G. M.; CABRINI, E. C.; TOYAMA, M. H.; NOVELLO, J. C.; MARANGONI, S.; MATOS, D. G. G. A trypsin inhibitor from Peltophorum dubium seeds active against pest proteases and its effects on the survival of Anagasta kuehniella (Lepidoptera: Pyralidae). Biochimica et Biophysica Acta, Amsterdam, v. 1621, n. 2, p. 170-182, 2003. DOI:10.1016/S0304-4165(03)00055-2

MERRIL, A.L.; WATT, B.K. Energy value of foods: basis and derivation. Washington: United States Department of Agriculture, 1973. 105p.

MICHELS, K. B.; FUCHS, C. S.; GIOVANNUCCI, E.; COLDITZ, G. A.; HUNTER, D. J.; STAMPFER, M. J.; WILLETT, W. C. Fiber intake and incidence of colorectal cancer among 76,947 women and 47,279 men. Cancer Epidemiology, Biomarkers \& Prevention, Philadelphia, v.14, p.842-849, 2005. DOI: 10.1158/1055-9965.EPI-04-0544

MUNHOZ, C. L.; GUIMARAES, R. C. A.; NOZAKI, V. T.; SANJINEZ-ARGANDOÑA, E. J.; HIANE, P. A.; MACEDO, M. L. R. Preparation of a cereal bar containing bocaiuva: physical, nutritional, microbiological and sensory evaluation. Acta Scientiarum. Technology, Maringá, v. 36, n. 3, p. 553-560, 2014. DOI: http://dx.doi.org/10.4025/actascitechnol.v36i3.18561

OLIVEIRA, M. E. B.; GUERRA, N. B.; MAIA, A. H. N.; ALVES, R. E.; MATOS, N. M. S.; SAMPAIO, F. G. M.; LOPES, M. M. T. Características químicas e físico-químicas de pequis da chapada do Araripe, Ceará. Revista Brasileira de Fruticultura, Jaboticabal, v. 32, n. 1, p. 114-125, 2010. DOI: http://dx.doi.org/10.1590/S0100-29452010005000030

OLIVEIRA, A. L.; ALMEIDA, E.; SILVA, F. B. R.; NASCIMENTO FILHO, V. F. Elemental contents in exotic Brazilian tropical fruits evaluated by energy dispersive X-ray fluorescence. Scientia Agricola, Piracicaba, v. 63, n. 1, p.82-84, 2006. DOI: http://dx.doi.org/10.1590/S010390162006000100013

OLIVEIRA-FILHO, E. C.; MEDEIROS, F. N. S. Ocupação humana e preservação do ambiente: um paradoxo para o desenvolvimento sustentável. In: PARRON, L. M.; AGUIAR, L. M. S.; DUBOC, E.; OLIVEIRA-FILHO, E. C.; CAMARGO, A. J. A.; AQUINO, F. G. (Ed) Cerrado: desafios e oportunidades para o desenvolvimento sustentável. Planaltina: Embrapa Cerrados, p. 33-61, 2008.

RAMOS, M. I. L.; RAMOS FILHO, M. M.; HIANE, P. A.; BRAGA NETO, J. A.; SIQUEIRA, E. M. A. Qualidade nutricional da polpa da bocaiuva Acrocomia aculeata (Jacq.) Lodd. Ciência e Tecnologia de Alimentos, Campinas, v. 28, p. 90-94, 2008. DOI: http://dx.doi.org/10.1590/ S0101-20612008000500015 
SALINAS, Y. G.; GARCIA, R. Métodos químicos para el analisis de suelos acidos y plantas forrajeras. Cali: Centro Internacional de Agricultura Tropical, 1985. 83 p.

SGARBIERI, V. C. Proteínas em alimentos proteicos: propriedades - degradações modificações. São Paulo: Varela, 1996. 517 p.

SILVA, A. G. M.; FERNANDES, K. F. Composição química e antinutrientes presentes nas amêndoas cruas e torradas de chichá (Sterculia striata A. St. Hill \& Naudin). Revista de Nutrição, Campinas, v. 24, n. 2, p. 305-314, 2011. DOI: http://dx.doi.org/10.1590/S141552732011000200011

SILVA, M. R.; LACERDA, D. B. C. L.; SANTOS, G. G.; MARTINS, D. M. O. Caracterização química de frutos nativos do cerrado. Ciência Rural, Santa Maria, v.38, n. 6, p.1790-1793, 2008. DOI: http://dx.doi.org/10.1590/S0103-84782008000600051

VALLILO, M. I.; TAVARES, M.; AUEDA-PIMENTEL, S.; BADOLATO, E. S. G.; INOMATA, E. I. Caracterização química parcial de Lecythis pisonis Camb. (Sapucaia). Acta Amazonica, Manaus, v. 28, n. 2, p. 131-140, 1998. DOI: http://dx.doi.org/10.1590/1809-43921998282140

VERA, R.; SOARES JÚNIOR, M. S.; NAVES, R. V.; SOUZA, E. R. B.; FERNANDES, E. P.; CALIARI, M.; LEANDRO, W. M. Características químicas de amêndoas de barueiros (Dipteryx alata Vog.) de ocorrência natural no Cerrado do Estado de Goiás, Brasil. Revista Brasileira de Fruticultura, Jaboticabal, v. 31, n. 1, p. 112-118, 2009. DOI: http://dx.doi.org/10.1590/S0100-29452009000100017 